\title{
Violência de gênero no campo da Saúde Coletiva: conquistas e desafios
}

\author{
Gender-based violence in Public H ealth: \\ challenges and achievements
}

Lilia Blima Schraiber ${ }^{1}$

Ana Flávia Pires Lucas d' Oliveira ${ }^{1}$

Ana Paula Portella ${ }^{2}$

Eleonora M enicucci ${ }^{1}$

${ }^{1}$ Departamento de

M edicina Preventiva,

FaculdadedeM edicina,

Universidade deSão Paulo.

Av. Dr. Arnaldo 455/2.245,

Cerqueira César.

01246-903 São Paulo SP.

liliabli@usp.br

${ }^{2}$ SOS Corpo - Instituto

Feministaparaa

Democracia.
Abstract Thistext deals with violence against women (VAW) as a scientific and practical object of $\mathrm{H}$ ealth. It is a theoretical and critical reflection related to historical processes that show convergences and distances between the approach of this violence as an issue and the health field particularities, cre ating contemporary conquests and challenges especially to Public $\mathrm{H}$ ealth. The text debates interdisciplinary aspects of this scientific object and some impacts to the knowledge production and to health actions. Considering the different scientific and practical cultures of $\mathrm{H}$ ealth and other fields that al ready deal with VAW, existing tensions between health perspective and violenceasa socio-cultural phenomenon are showed, becoming critical when added the gender approach. Challenges are then created on dialogs between those fields in terms of: paradigms, scientific models and languages of each one; social intervention needs in every field; and the distinct relation between knowledge and social intervention presented in each field. On the other hand, the conquests related to human and social rights and the proposal of integral health are shown as convergences between these fields. To conclude, some possible answers to the challenges are considered.

Key words Gender violence, Interdisciplinary, Integrality in health, Humans and social rights in health
Resumo Este texto trata da violência contra muIheres (VCM) como objeto científico e prático da Saúde. É uma reflexão teórica crítica concernente a processos históricos que permitem ver tanto as convergências como os afastamentos entre a tomada dessa violência como questão e particularidades do campo da Saúde, produzindo conquistas e desafios atuais em especial para a Saúde Coletiva. 0 texto debate aspectos interdisciplinares desse objeto científico e suas implicações para a produção do conhe cimento e para as ações em saúde. Considerando as distintas culturas científicas e práticas da Saúde e outros campos quejá lidam com VCM , mostram-se tensões existentes entre a perspectiva da violência como questão da saúde e como fenômeno sociocultural, ampliadas com o acréscimo da abordagem de gênero. Produzem-se então desafios de diálogo entre esses campos em termos de paradigmas, model os científicos e linguagens de cada qual; as necessidades de intervenção social em cada campo; e a relação distinta que cada um possui entre conhecimentos e intervenção social. De outro lado, mostram-se como convergências entre esses campos as conquistas re lativas aos direitos humanos e sociais e a proposta desaúde integral. Conclui-se com al gumas possíveis respostas aos desafios.

Palavras-chave Violência de gênero, Interdisciplinaridade, Integralidade em saúde, Direitos humanos e sociais em saúde 
Violência como questão do social e da Saúde

Violênciaéreconhecida como fenômeno sociocultural, em sua origem e repercussões, e quase sempre concebida como atinente à segurança pública e ao judiciário ${ }^{1}$. Reconhecêla como uma questão também da Saúde, portanto, não é al go fácil e a precedência histórica de sua abordagem pelas Ciências Humanas e Sociais reforça esse ponto de vista.

De fato, é cronologicamente mais tardia a tomada da violência como objeto do campo da Saú$\mathrm{de}^{2-4}$, em particular da violência contra as mulheres, a qual éfrequentemente apontada como estranha aos escopos da atuação profissional, não obstante serem os danos físicos ou mentais consequentes à violência reconhecidos pelos profissionais como desuas competências 5 . Ademais, na Saúde, é a Saúde Coletiva a que mais se aplica ao problema, buscando, para tal, referências em sua base interdisciplinar ${ }^{6}$.

Colonizada pela cultura científica e profissional originária da medicina, a Saúde Coletiva já possui diversos desafios, devendo enfrentar uma questão particular no caso da violência: como assumi-la e evitar cisões internas ao seu próprio domínio.

As cisões manifestam-se de três modos. Um primeiro reside na abordagem biomédica em que os danos físicos e mentais são abordados, mas a violência não o é, separando-se a causa de seus efeitos e impedindo a perspectiva integral da saúde. M ais radical que os demais, este modo situa a violência como uma não questão, dispensando seu estudo. Outro modo, pautado no mesmo reducionismo biomédico, é aquele pelo qual os profissionais de saúde até se dispõem, alguns, a lidarem com a violência, fazendo-0, porém, como atuação pessoal e não profissional 5 .

Cabe considerarmos que, desqualificando a violência como questão, opera-se uma clivagem entre os adoecimentos e seus desencadeantes, separando-se as doenças de seus fatores de risco. Este procedimento seria incomum em relação aos adoecimentos de modo geral e estranho à clínica e à epidemiologia, que são os saberes fornecedores dastecnologias de interven ção na Saúde. N esse sentido, ao tratar dos casos de violência apenas por seus efeitos, contentar-se-ia a prática médico-sanitária com tecnologias "incompletas" desde seu próprio ponto de vista, pois totalmenteinsuficientes da perspectiva da prevenção em saúde.

0 terceiro modo é o desenvolvimento diverso entre os conhecimentos científicos ea prática, imprimindo-se direções diferentes para a produção dos conhecimentos relativamente à criação das formas de interven ção. 0 conhecimento, nessecaso, perde sua capacidade tecnológica de prover um saber acerca da violência que resulte em ações assistenciais e preventivas nos serviços de saúde.

Os desafios são, portanto, de construção, na Saúde, de um conhecimento interdisciplinar eque resulte em articulação com as práticas do campo. Para a violência de gênero contra mulheres, queéo nosso objeto de consideração neste texto, tal questão foi, em parte, tratada por $\mathrm{Castro}^{7}$, ao afirmar, inspirado em Kant, que, na literatura, encontraremos "ou teoria sem dados, ou empirismo cego". Reclama o autor da ausência do diálogo e do equilíbrio entre a produção de conceitos e a de dados empíricos. Esta última é, a nosso ver, a base da qual se extraem propostas de intervenção sobre os atos violentos e seus contextos e, por isso, acrescentamos ao apontado pelo autor outra ausência nos estudos: a articulação entre a ciência (na articulação teoria - dados empíricos) e a atenção em saúde. Sem esta articulação, o conhecimento produzido não gera tecnologia de ação correspondente, restando o campo sem propostas de assistência aos casos ou de prevenção e promoção da saúde, isto é, desempenhos técnicos de base científica para os profissionais sobre a violênciå.

Examinaremos esses desafios, mostrando confluências e afastamentos que ocorrem na perspectiva interdisciplinar do problema.

\section{Violência de gênero contra mulheres: interfaces com a Saúde eas zonas problemáticas}

Chamamos de zonas problemáticas os aspectos conflitantes entre distintas culturas de pesquisa e de intervenção social, quando tomam a violência de gênero contra as mulheres ${ }^{8}$. São conflitos entre o modo como as Ciências Sociais e H umanas, de um lado, e a Saúde, de outro, podem lidar com essa violência, esão, ainda, conflitos no interior do próprio campo da Saúde. Seu reconhecimento é importante, pois atuam como obstáculos ao agir científico e profissional, mesmo quando não estejam claros para pesquisadores, formuladores e gestores da política ou para os profissionais dos serviços de saúde.

As raízes desses conflitos são a origem e o desenvolvimento do tema "violência" como uma questão, construindo histórias que serão distintas, no campo das ciências do social relativamente ao da saúde, gerando expectativas diversas quanto à sua aceitação ou rejeição em cada campo.

Como acontecimento sociocultural, violência é definida por atos que constituem violação de direi- 
tos, da perspectiva legal etambém ética9 ${ }^{9}$ M as violência também é definida como uso instrumental de poder, situação em que o sujeito detentor de maior poder se vale daqueles atos para reiterar ou ampliar seu poder, o que não Ihe dá legitima autoridade senão um poder coercitivamenteinstaurado ${ }^{10,11}$. Isto acentua desigual dades sociais, como as degênero, e nega relações interativas/comunicativas.

Por essas definições, a violência se estabelece como objeto de denúncia ético-política, pois os estudos que assim a tomam assumem o estatuto de crítica da sociedade e sua cultura. Tais implicações, quando aceitas como parte do modo de produzir ciência, exigem da metodologia o exercício de uma contínua vigilância epistemológica para garantir a objetividade do conhecimento ${ }^{12}$. Isso ocorre com diversos objetos em determinados estudos nas ciências do social. No entanto, no caso da violência contra mulheres, adiciona-se 0 fato de que esse objeto será também alvo de políticas assertivas de equidade social e de emancipação das mulheres. A relação entremovimento social eprodução científica se fez bastante intensa na história da tomada dessa violência como questão, adensando conceitual e empiricamente as relações e desigual dades de gênero e apontando para o compromisso de aplicação dos resultados das pesquisas em prol de leis ou normas protetoras dos direitos ${ }^{13,14}$. Este caráter aplicado não tem sido usual das ciências do social, particularmente no Brasil, e não se o vê necessariamente nos demais objetos de estudo, sendo, pois, contribuição específica da colaboração entremovimento feminista e produção científica.

Ao longo dessa história, produziram-se, então, conquistas legais-jurídicas implementadas em políticas públicas de equiparação de direitos, como parte dos movimentos contraculturais reformadores da relação de gênero tradicional, que atribuem desempenhos eresponsabilidades desiguais aos indivíduos de sexo masculino e feminino, com maior valor social e poder para os primeiros. É desse modo que, em meados dos anos setenta, 0 movimento feminista contrapõe à tese jurídica da "legítima defesa da honra" o lema "quem ama não mata". O põe-se, assim, aos crimes ditos passionais, cujos agressores eram absolvidosjudicialmente do assassinato de suas esposas ${ }^{15}$. Instaura-se a violência contra a mulher como questão social, ao tempo em quese constitui temática de estudo para as ciências sociais e jurídicas. Articuladamente, 0 movimento exerce ainda pressões de militância junto ao sistema judiciário, para o reconhecimento de direitos das mulheres em leis. 0 processo culmina com a criação em meados dos anos oitenta deserviços específicos: as delegacias especiais para mulheres, lócus de captação dos casos de violência de gênero contra a mulher ${ }^{15}$.

Para a Saúde Coletiva, essa história produziu aproximações. Primeiro, convergiu nesse caráter de ciências mais aplicadas, caráter que a Saúde detém desde suas origens modernas. Outra convergência foi o profundo entrelaçamento entre a proposição deum campo científico ea crítica social ${ }^{16,17}$. Por sua própria origem e desenvolvimento como campo, a problemática dos direitos humanos e sociais, assim como a elaboração de projetos e políticas de maior equidade social, não Ihe foram estranhos. Ao contrário, a Saúde Coletiva nasce de uma crítica à medicina e à saúde pública hegemônicas e com pretensões políticas de reforma social ${ }^{17}$.

Ao definir-se como um campo, dispôs-se a trabalhar explicitamente com duas articulações: a M edicina com a Saúde Pública e a dos saberes de cada qual com as respectivas práticas na rede de serviços de seu sistema de atenção. Nisto, criticou abertamente os silêncios em torno à necessidade de tais articulações, como se dos saberes derivassem mecanicamente as práticas, para a M edicina e para a Saúde Pública, e como se da M edicina derivasse a própria Saúde Pública. Estes são silêncios ideológiCOS, a que se contrapõe o pensamento crítico ${ }^{18}$.

Constituiu-se, então, a Saúde Coletiva ${ }^{16,17}$ sendo esta uma formulação brasileira - como uma reorientação da Saúde Pública tradicional em aproximação da M edicina, mas simultaneamente cursando com uma dupla crítica a esta última. Primeiro, a crítica à fragmentação do ato médico e sua progressiva especialização, configurada nos movimentos americanos de reforma médica que formulam a medicina integral, a preventiva ea comunitária. O utra, a crítica à própria medicina preventiva ali proposta, pela leitura conservadora e liberal com que a proposta operava a Saúde, construída como questão individual e não social, no que isentava o Estado de qualquer responsabilidade em seu provimento ou regulação. 0 termo "coletiva" adicionado à Saúdepretendeu anunciar esta crítica à soberania do individualismo, ressaltando os deveres do Estado para com sua população. 0 feliz termo, por sua vez, ao não se restringir à noção de "público", mas ao compô-la em seu interior, expandiu a competência do campo para os domínios da vida privada e do individual, espaços de eleição já tradicionais da M edicina.

Emergindo nos anos sessenta e setenta, constituiu-se no país no período da ditadura militar e das lutas por mel hores condições de vida, contra a pobreza e a carestia. Toda uma cooperação ocorrerá entre os pesquisadores das universidades e os militantes dos movimentos sociais para a demo- 
cratização do próprio Estado, surgindo a Saúde Coletiva como campo de reforma sanitária e de reforma social, com releituras das políticas, das instituições prestadoras de serviços, tanto quanto das necessidades de saúde.

Neste movimento, de um lado, o campo abrese ao social e ao cultural para compor seus saberes e práticas, sob o concei to de integralidade. De outro, progressivamente constitui como sua competência produzir conhecimentos e atuar nas políticas de saúde, no planejamento, gestão e avaliação dos serviços, e no provimento de atenção integral à saúde da população em todos seus segmentos.

No que tange especificamenteàs mulheres, fica evidente a convergência desses propósitos com aqueles da tomada da violência de gênero contra a mulher como questão social ecientífica. Quase uma década após o início das lutas feministas e à época da criação das delegacias especiais (DDM ou DEAM ), o movimento de mulheres propõe em conjunto com pesquisadores e profissionais da Saúde, em 1984, o Programa de Atenção Integral à Saúde da Mulher (PAISM) $)^{19,20 .}$

O PAISM, porém, não tratou de imediato da violência, mas da reprodução humana, baseandose na crítica ao modo como se tomava a mulher nas práticas em Saúde. Formulou uma perspectiva de saúde reprodutiva como movimento contracultural ao projeto biomédico de abordar a mulher apenas em sua condição maternal, medicalizando o corpo feminino ao reduzi-lo às suas partes com capacidade reprodutora. A concepção materno-infantil da Saúde da Mulher havia dado conta, no plano simbólico e material, de toda essa construção em que não havia questão das mulheres sem que de imediato fosse também questão de infância, assim como não havia mulher fora da identidade de ser mãe. Com o lema "nosso corpo nos pertence" 19 é que se proporá essa outra abordagem da mulher e de sua saúde pelos saberes e práticas da SaúdeColetiva, elaborando-seo PAISM com o reconhecimento e integralidade da tomada de suas múltiplas necessidades em saúde.

Em sua particular história, na Saúde, a violência contra a mulher emerge relacionada, primeiro, à prática médica do aborto legal, direito estabelecido nos anos quarenta e prática permitida só em casos de estupro e risco de vida para a mãe, com o estabelecimento, em 1989-90, do primeiro serviço hospitalar em São Paulo 3,17,19. Este fato produzirá determinadas representações da violência, associando-a com o estupro - a violência sexual por estranhos, já que nem legal nem culturalmente se reconhecia o estupro marital. Essa especificidade é bastante diversa da principal modalidade de agres- são que caracteriza a violência de gênero contra as mulheres, majoritariamente do tipo conjugal. Também o fato de que a prática dos médicos nestes casos fosse subordinada à decisão jurídica, configurando mais o exercício de uma terapêutica do que uma questão de saúde-doença, produziu simbolicamenteo efeito de estabelecer a violência como questão mais do judiciário do que da assistência à saúde. Daí assumirem-se apenas as lesões no corpo das mulheres como objeto próprio das competências da Saúde, não parecendo aos profissionais desse campo que a violência, ainda que causa daqueles danos, fosse também parte dessas competências.

Assim, observa-se, sobretudo a partir dos anos 1995 até o momento, um grande envolvimento da Saúde Coletiva com a tomada da violência como questão, formulando políticas específicas, muitas propostas de pesquisas e de programas de intervenção. N essa trajetória, começam a surgir obstáculos que são desafios para a plena consecução das políticas e desenvolvimento das práticas assistenciais nos serviços, apontan do para divergências na tomada da violência de gênero como questão entre o domínio do Social e o da Saúde.

Examinemos primeiro esse destaque dado à violência sexual, em contraposição às de tipo físico ou psicológico cometidas por familiar ou parceiro, no âmbito doméstico. Produto da particular história da violência contra mulher como alvo da Saúde, tal destaque se mantém atéhoje, como mostram os programas de intervenção - desde a norma técnica para a violência sexual aos projetos diversos de implantação de serviços de violência, predominantemente voltados a essa modalidade. Ocorre aqui um contraste com o plano das pesquisas em Saúde, que se desenvolve quase com o destaque oposto, centrando na violência de natureza doméstica, muitas vezes denominada por parceiros íntimos, cuja modalidade sexual também é existente, ainda que represente acontecimento diverso daquela mesma designação geral. A nomeação algo imprecisa, em que ao termo "violência sexual" associa-se o estupro por estranhose ao termo "violência doméstica" associa-se a violência física perpetrada por familiar ou parceiros, obscurecendo o tipo sexual queaí também pode ocorrer, é indício de uma autonomia operada entre as expressões da violência de gênero, mais um desafio ao campo. A confusão terminológica podelevar a uma divergência simbólica ea uma imprecisão conceitual, retirando até mesmo 0 caráter degênero do estupro cometido por estranhos. 0 estupro é muitas vezes relacionado à pobreza ou às desigualdades socioeconômicas, como se pertencesse, sobretudo, ao domínio da violência estrutural ou urbana. Raramente é explorado como um 
comportamento assemelhado, culturalmente, à violência doméstica, dados os mesmos referenciais degênero.

Outro desafio é o das relações entre essas violências urbana e doméstica, que, em particular na Saúde, são tratadas em recortes de abordagem separados e diferentes ${ }^{21}$. A violência urbana é tomada como questão pelos estudos epidemiológicos no recorte da mortalidade por causas externas, situação em que domina a violência entrehomens, 0 que raramente é examinado da perspectiva de gê nero. Já a doméstica, situação em que a violência ocorre predominantemente contra as mulheres, as crianças ou os idosos, quase nunca é explorada em seu lado fatal. Estudo realizado para Pernambuco, entre 2002 e 2007, aponta o fato de que $45,8 \%$ dos homicídios contra mulheres aconteceram em suas residências, sendo tão majoritariamente perpetrados por familiares, a ponto de, em 2007, estes últimos serem agressores em cerca de $70 \%$ dos homicídios. Os parceiros ou ex-parceiros são os perpetradores da grande maioria desses casos. Esses dados mostram os homicídios de mulheres como possível resultado da própria violência doméstica por parceiros, diferenciando-se do perfil dos homicídios masculinos ${ }^{22}$.

Para completarmos melhor esse quadro, contudo, será preciso examinar as próprias peculiaridades da violência contra a mulher pelas quais foi conceituada como questão de gênero, cotejandoas com exigências do campo da Saúde em termos de suas necessidades de conhecer e intervir para afirmar-se como campo.

Violência contra a mulher como questão de gênero: contribuições e desafios na Saúde

As situações de violência contra mulheres são as de agressões interpessoais ou assédios muito frequentes eque podem ser do tipo sexual, físico ou emocional, apresentando-se na grande maioria de modo combinado, superpondo-se os tipos entre $\mathrm{si}^{21}$. 0 principal agressor é em mais de $80 \%$ das vezes 0 parceiro íntimo ou ex-parceiro, cuja intimidade das relações resulta em episódios repetidos e de gravidade crescente ${ }^{23,24}$. Não obstante serem as agressões físicas ou emocionais as que mostram as taxas maiores de ocorrência, a marca distintiva das situações entre homens e mulheres é a do tipo sexual, pois as taxas encontradas são muito maiores para mulheres do que para homens $\mathrm{s}^{25,26}$.

Outra marca distintiva de gênero é o fato de que, mesmo ocorrendo com tamanha frequência, essas situações não são reveladas facilmente. Ao contrário, a violência de gênero marca-se pela invisibilidade ${ }^{8,22}$, a mesma que tem acompanhado questões afetivas e íntimas da vida doméstica e privada para as ciências do social, em geral.

A tomada, portanto, desses vividos como questões de conhecimento ou deintervenção social corresponde à tomada das interações afetivas e íntimas pelas ciências e políticas públicas, produzindo novas normatizações do ponto de vista ético etambém legal. Se na esfera pública da sociedade existe, desde longo tempo, uma definição de virtudes e legalidades necessárias ao "adequado comportamento", uma pauta similar passa a ser pensada para a esfera privada, atuando nas relações de parcerias conjugais. D eterminados atos, historicamente tidos como possíveis, são, hoje, violências. A célebre alegação "ela me faz perder a cabeça", citada por muitos estudos como principal argumento, sobretudo masculino, justificador da violência e com aceitação cultural nas relações afetivo-sexuais ${ }^{8,9}$, é hoje objeto de regulação: homens e muIheres devem, doravante, buscar outra forma de lidarem com os conflitos.

Destaquemos que essa aceitação cultural produz eé produzida pela banalização e naturalização das violências. Homens e mulheres apresentam argumentos diversos entre si para a naturalização do comportamento, mas compartilham a banalização de sua ocorrência, com impactos para cada situação de gênero em termos do que conotar como violênciae do que constituir como questão $0^{27}$. Produzem-se, assim, diferentes dinâmicas de revelações e invisibilidades seja para diversos contextos sociais, seja para distintas identidades de gênero e nestas, intra ou inter gênero.

Contudo, há contextos que favorecem a aceitação da violência de gênero contra as mulheres, encontrando-se as maiores taxas nos países que apresentam as seguintes situações: quando há normas culturais ou legais conferindo direito de propriedade masculina sobre as mulheres; quando há controle masculino sobre a riqueza da família; em contextos em que a masculinidade está associada à dominação e soberania, com maior liberdade e poder de delimitar comportamentos, sobretudo os das mulheres e em público, mas também privadamente, em nome da honra masculina; e quando há consenso de que o controle final das decisões é masculino ${ }^{24,28}$. A violência de gênero expressará, deste modo, um ato masculino para a aculturação da mulher nos referentes do mais antigo e maior poder do masculino, que é o patriarcado. Em crises ou ameaças de ruptura dessa dominação tradicional, comportamentos de reconquista do poder e da autoridade perdidos ou simplesmente de pre 
venção dessa perda serão não só possíveis, no universo simbólico da masculinidadehegemônica, mas necessários.

É por essa ordem cultural e moral que as muIheres que estão ou estiveram em situações de violência desenvolvem sentimentos contraditórios relativos a tais experiências. Sentem-se envergonhadas ou humilhadas, culpadas pela violência, temendo por sua segurança ou a de seus filhos. Pensam frequentemente que não possuem controle sobre suas vidas mas, ao mesmo tempo, esperam que 0 agressor mude ou querem proteger o parceiro, por razões econômicas ou afetivas ${ }^{24,28}$. Pelas mesmas razões, pessoas do contexto social mais próximo não estranham as ocorrências ou não crêem que devam intervir. A invisibilidade da violência contra a mulher e a recusa em seu estabelecimento como questão ocorrem mesmo para o campo do social, acentuadas pelas questões de gênero que originam a própria violência.

Constituem, portanto, contribuições muito relevantes os estudos que, nas ciências sociais e humanas, assumiram esse objeto e o referencial de gênero. Deles se extrai uma grande e diversa produção teórico-conceitual, com alto potencial explicativo das situações e que, no âmbito do sociocultural, inscrevem a interação entre dois sujeitos, a desigualdade de poder e a dominação masculina como objeto de suas pesquisas. Contribuíram assim para a valorização da vida privada, das emoções e do cuidar como objetos científicos e até então pouco presentes nas pesquisas.

A mesma contribuição estende-se ao campo da Saúde no sentido de valorizar dimensões específicas da vida privada ${ }^{29}$, tais como as relações de gênero em família ${ }^{30}$. I sto se somou à valorização já dada para aspectos da vida privada em Saúde, cujos saberes e práticas o fazem desde seu modo de apreender individualmente os casos, até a leitura médica mais tradicional de responsabilização do indivíduo pelos comportamentos (de risco), ocasionando seu adoecimento ${ }^{31}$. Ressaltando o lado populacional dos adoecimentos, contudo, teremos a Epidemiologia, de modo geral. Além disso, uma valorização do social éparticularmente dada a partir dos anos setenta e na corrente de pensamento da Epidemiologia Social, sobretudo a latino-americana, quando busca apropriar-se de referências das ciências sociais e humanas para compor suas perspectivas epistemológicas e científicas, ocupando também no Brasil importante terreno ${ }^{32}$.

$M$ as é de se notar que esse contraponto do social ao individual feito pela Epidemiologia, mesmo a Social, quase sempre reside na tomada das desigualdades socioeconômicas como questão. Vale dizer, é no referencial de classes sociais, ou de populações de baixa renda/pobreza que o social será valorizado na Saúde. Não obstante e com mais dificuldades de penetração no campo, uma epidemiologia que se vale conceitual e metodologicamente do conceito de gênero também atualmente seestabelece.

Todavia, entre a perspectiva mais social e a médico-sanitária no trato das questões de gênero, algumas diferenças de tradições científicas e de constituição de campos de conhecimentos e intervenções devem ser apontadas. Primeiro, a qualidadediversa da explicação da realidade vivida como violência de gênero contra as mulheres. Como ocorrência sociocultural, a violência de gênero tem boa parte da produção de conhecimento em estudos nos quais a explicação repousa na compreensão e interpretação da realidade empírica, modalidade bem diferente da explicação causal buscada pela Epidemiologia e necessária ao campo da Saúde, como veremos. Também a adoção da pesquisa qual itativa permiteapontar para condições depossibilidades socioculturais de existência. Assim, dá destaque à gama diversa de possíveis como sua qualidade de conhecer. E isto é diverso da qualidadedeconhecimento buscada pela Epidemiologiae, diga-se novamente, necessária ao campo da Saúde, voltado para o predomínio e a regularidade quer do evento estudado - de que se extrai a importância como acontecimento populacional por sua magnitude -, quer de suas associações estatísticas com fatores do social e do cultural, ea potencialidade derivada de previsão estatística de ocorrência do evento, gerando a noção de risco $0^{8,31,33}$.

Por que insistimos em apontar essas qualidades diferentes no conhecimento da Saúde e as tomamos como necessidades para o campo? Porque a Saúde é um campo muito tecnológico e isso assim ocorre porque seus cientistas orientaram 0 modelo de ciência para a produção das muitas tecnologias (equipamentos, medicamentos, intervenções cirúrgicas) desde sua constituição moderna ${ }^{34}$. A modernidade, de modo geral, orientou toda a produção de conhecimentos para um sentido mais prático. N a medicina ena saúde pública, esse caráter pragmático está bem acentuado, na grande aplicabilidade dos conhecimentosquebuscam produzir. Constituíram por isso saberes que operam a mediação entre suas ciências, ditas básicas - biomédicas, demográfica ou estatística - eo uso delas na produção (trabal ho) social: os saberes tecnológicos que orientam todo 0 ato médico ou o sanitário, como o são a clínica e a epidemiologia ${ }^{31,34}$. Por isso, teremos uma grande necessidade de delimitar o vivido em recortes empíricos bem individualiza- 
dos e precisos, o queér realizado pelo procedimento de reduzir a vida social e cultural a particulares analiticamente tomados em uma fragmentação e fatoração do social, do humano e do natural, a que o paradigma positivista biomédico respondeu muito bem. Tal proceder, que implica uma leitura redutora dos vividos, apresenta limitantes para 0 conhecimento que é produzido, mas, por outro lado, mostrou grande êxito histórico para as intervenções no social.

O campo produziu tais efeitos não só nas pesquisas, mas também nas representações do que seja sua boa intervenção, isto é, boa prática assistencial: os êxitos da redução biomédica geram uma cultura tecnológica que identifica boa prática à competência terapêutica, subsequente a um diagnóstico bastante pragmático. Esteé que produz as possibilidades imediatas de intervenção, dotando a prática de um caráter técnico e um sentido muito peculiar de urgência quanto à resolução de demandas. É, ain$\mathrm{da}$, acionador das tecnologias materiais, expandindo esse tipo de intervenção para todos os objetos que assume como seus, como quando recorre universalmente a medicamentos como a boa assistência para qualquer caso (inclusive os de violência). N esse sentido, fazer algo e preferencialmente uma intervenção manual e imediata sobre o caso parecerá sempre melhor do que observar, aguardar ou orientar. Reconheceremos nesse processo o movimento medicalizador e altamente tecnicista de que se acusa criticamente a medicina contemporânea.

Isto fará representar como próprios à medicina, e por hegemonia desta no campo da Saúde, próprios à Saúde como um todo, objetos cuja intervenção possibilite este acionamento dos recursos tecnológicos materiais. A Saúde, assim colonizada, dificilmente compreenderá o cuidado como al go além da terapêutica medicamentosa ou do uso de procedimentos à base das tecnologias materiais, tais como as intervenções do tipo cirúrgico, mesmo que de pequeno porte. Isto seguramente impõelimites dereconhecimento identitário a questões como a violência de gênero contra mulheres. Promove-se uma recusa profissional euma invisibilidadetecnológica, a reforçar as outras invisibilidades já mencionadas.

Esses modos de silenciar a violência de gênero ou ocultá-la constituem obstáculos não só práticos, como acima, mas científicos, em razão das dificuldades para se conhecer ereconhecer a diversidade das realidades vividas nas referências paradigmáticas exigidas pelo campo. Alertamos, porém, queao pontuarmos tais necessidades do campo não queremos de modo al gum reiterar o paradigma dominante da redução biomédica ou da fragmentação do sociocultural. A ênfase que demos nesses aspectos tecnológicos diz respeito aos desafios que constituem as inovações científicas e práticas exigidas pela tomada da violência de gênero como questão sem romper o diálogo com a Saúde. Trata-se, assim, do desafio em formular essa violência nos marcos de uma interdisciplinaridade tanto conceitualmente quanto tecnologicamente, tendo por referência, a nosso ver, o paradigma da integralidade em saúde.

Violência de gênero contra mulheres como questão da saúde integral: desafios científicos e práticos

Reconhecendo-sea complexidade desse objeto, que articula domínios médico, sanitário, social ecultural, devemos considerar a insuficiência de disciplinas isoladas para dar conta de sua apreensão e transformação. A colaboração interdisciplinar deve assim dirigir-se a esforços como os que seguem.

Primeiro, nos desenhos de pesquisa, articular a reflexão conceitual com as investigações empíricas mais delimitadas, identificando os vários equivalentes empíricos do conceito mais abstrato de violência. A concretização e a busca de delimitações das diversidades, tais como a dos tipos psicológico ou emocional, físico, sexual; ou interpessoal, institucional ecoletiva; ou estrutural eurbana, etc., não podem, porém, obscurecer o fato de que sejam delimitações relacionadas às teorias adotadas. Assim, todas elas adquirirem o significado de violência, tal como as ações que se proponham para intervenção significam afirmações éticas dos direitos humanos e das mulheres, além de compromissos políticos de maior equidade de gênero e social.

Um segundo esforço será adensar e precisar melhor a própria construção teórica, distinguindo violência de comportamento natural, assim como mostrando suas relações com as questões de poder e autoridade, mas distinguindo-a de relações de poder autorizadas (legitimadas); ou mostrando 0 entrelaçamento das questões de gênero com as de desigualdades socioeconômicas e das questões da esfera pública com as da vida privada. Esse adensamento teórico não invalida definições operativas para os estudos empíricos, sem, contudo, se perder a perspectiva de sua qualidade restrita, de que deriva uma vida temporária para essas definições.

Outro esforço representa estabelecer definições e linguagens para abordar o não patológico, buscando-se melhores canais e modos de comunicação. Isto implica aprender a trabal har com as emoções e a posicionar-se de modo claro em termos 
éticos e políticos, como cientistas e profissionais. De um lado, o tema evoca e mobiliza fortes emoções no relato ena escuta, e de outro, pode identificar ou desencadear situações de risco de morte, implicando um aprendizado para se lidar com questões de segurança pessoal, além das emoções, quando se toma a violência como objeto.

Por fim, cabe comentar um esforço de desconstrução da noção de igualdade que está posta na Saúde, sobretudo relacionada às tecnologias assistenciais. Porque é da cultura assistencial, com base na redução biomédica, a apropriação ideológica de uma igualdade dada apenas pela igualdade essencial dos corpos, raiz, até, da naturalização dos comportamentos culturalmente construídos. Isto gera a cultura que identifica boa prática e bons serviços à neutralidade política e intersubjetiva como ideologia tecnológica eocupacional. Somen- te o plano das lesões do corpo seria neutro, exteriorizando-se da boa técnica o social, o racial, o gê nero, a subjetividade. Ao mesmo tempo em que seriam neutras, tais intervenções sobre o corpo seriam também justas, pois desprovidas das crenças, preferências, valores e emoções dos profissionais. N estes termos, a prática seria igual itária ejusta se cumprisse com essa neutralidade; qualquer acolhimento diverso évisto como adoção deprivilégios, não como realização de direitos. Essa ideologia implica, então, sérias questões para a busca das equidades, já dados os diferenciais de oportunidades e deaten ção delimitados pelas desigual dades sociais e de gênero. Será, pois, um dos maiores desafios na Saúde o esforço contrário: o de situar o agir profissional no compromisso com os direitos humanos e das mulheres, e com a maior equidade nas questões de gênero.

\section{Colaboradores}

LB Schraiber concebeu e fez a primeira versão do artigo eas demais autoras contribuíram igualmente na redação final do texto.

\section{Referências}

1. Dahlber LL, Krug EG. Violence - a global public health problem. In: Krug EG, Dahlber LL, M ercy JA, ZWI $A B$, Lozano R. World report on violence and health. Genebra: World Health Organization; 2002. p. 1-22.

2. M inayo MCS. The Inclusion of violence in the health agenda: historical trajectory. Cien Saude Colet 2006; 11(2):375-383.

3. Pitanguy J. Violência de gênero e saúde. Intersecções. In: Berquó E, organizadora. Sexo \& vida. Panorama da saúde reprodutiva no Brasil. São Paulo: Ed. Unicamp; 2003. p. 319-337.

4. Schraiber LB, d'Oliveira AFPL. Violência contra as mulheres: interfaces com a saúde. Interface - Comunic., Saúde, Educ. 1999; 3(5):11-27.

5. Kiss LB, Schraiber LB. Temas médico-sociais e a intervenção em saúde: a violência contra mulheres no discurso dos profissionais. Cien Saude Colet. No preIo.

6. M inayo MCS. A Violência social sob a perspectiva da Saúde Pública. Cad. Saude Publica 1994; 10(supl.1): 7-18.

7. Castro R, Riquer F. La investigación sobre violencia contra las mujeres en América Latina: entre el empirismo ciego y la teoría sin datos. Cad. Saude Publica 2003; 19(1):135-146.

8. Schraiber LB, d'Oliveira AFPL, Couto MT. Violência e Saúde: contribuições teóricas, metodológicas e éticas de estudos da violência contra a mulher. Cad. Saude Publica. No prelo 2008.

9. Schraiber LB, d'Oliveira AFPL, Falcão MTC, Figueiredo WS. Violência dói e não é direito. A violência contra a mulher, a saúde e os direitos humanos. São Paulo: UNESP; 2005.

10. Arendt H. Sobre a violência. Rio de Janeiro: Relume Dumará; 1994. 
11. Costa JF. Violência e psicanálise. Rio de Janeiro: Edições Graal; 1986.

12. Bourdieu P, Chamboredon JC, Passeron JC. A profissão de sociólogo: preliminares epistemológicas. Petrópolis: Vozes; 1999.

13. Oliveira EM, Vilella W. O campo da saúde coletiva à luz das relações de gênero: um diálogo difícil e conflituoso. In: Swain NT, Muniz GD, organizadores. MuIheres em ação: práticas discursivas, práticas políticas. Florianópolis: Editora das Mulheres; 2005. p. 101-120.

14. Giffin K. Violência de Gênero, Sexualidade e Saúde. Cad. Saude Publica 1994; 10(supl 1):146-155.

15. Barsted LL. O campo político-legislativo dos direitos sexuais e reprodutivos no Brasil. In: Berquó $E$, organizadora. Sexo \& vida. Panorama da saúde reprodutiva no Brasil. São Paulo: Ed. Unicamp; 2003. p. 79-94.

16. Paim JS, Almeida Filho N. A crise da Saúde Pública e a utopia da Saúde Coletiva. Salvador: Casa da Qualidade Editora; 2000.

17. Schraiber LB. Saúde Coletiva: um campo vivo. In: Paim JS. Reforma Sanitária Brasileira. Contribuição para a compreensão crítica. Salvador: Edufba; Rio de Janeiro: Fiocruz; 2008. p. 9-19.

18. Chauí MS. Cultura e democracia. 0 discurso competente e outras falas. São Paulo: M oderna; 1981.

19. Corrêa S, Ávila MB. Direitos sexuais e reprodutivos. Pauta Global e percursos brasileiros. In: Berquó E, organizadora. Sexo \& vida. Panorama da saúde reprodutiva no Brasil. São Paulo: Ed. Unicamp; 2003. p. 17-78.

20. d' Oliveira AFPL; Senna DM. Saúde da Mulher. In: Schraiber LB, Nemes MIB, M endes- Gonçalves RB. Saúde do Adulto. Programas e Ações na U nidade Básica. São Paulo: Hucitec; 1996. p. 86-108.

21. Schraiber LB, d'Oliveira AFPL, Couto MT. Violência e Saúde: estudos científicos recentes. Rev. Saude Publica 2006; 40 (N esp):112-120.

22. Portella AP. Caracterização dos homicídios de muIheres em Pernambuco, 2002-2007. Boletim Dados e Análises 2008; IV (7): 2-6.

23. Garcia-M oreno $C$, Jansen $H A$, Ellsberg $M$, H eise $L$, Watts $\mathrm{CH}$, WHO Multi-country Study Team. Prevalence of intimate partner violence: findings from the WHO multi-country study on women's health and domestic violence. Lancet 2006; 368:1260-1269.

24. Heise $L$, Garcia-M oreno C. Intimate partner violence. In: Krug EG, Dahlber LL, M ercy JA, ZWI AB, Lozano R. World Report on Violence and Health. Genebra: World Health Organization; 2002. p. 87-121.
25. Tjaden $\mathrm{P}$, Thoennes $\mathrm{N}$. Prevalence and consequences of male-to-female and female-to-male intimate partner violence as measured by the national violence against women survey. Violence Against Women 2000; 6(2):142-161.

26. Schraiber LB, d'Oliveira AFPL, França-Junior I. Violência sexual por parceiro íntimo entre homens e mulheres no Brasil urbano, 2005. Rev. Saude Publica 2008; 42(Supl 1):127-137.

27. Couto MT, Schraiber LB, d'Oliveira AFPL, Kiss LB. Concepções de gênero entre homens e mulheres de baixa renda e escolaridade acerca da violência contra a mulher, São Paulo, Brasil. Cien Saude Colet 2006; 11(Supl.):1323-1332.

28. Heise L, Ellsberg M, Gottemoeller M. Ending violence against women. Population Rep. 1999; 27:1-43.

29. Oliveira EM . O feminismo desconstruindo e reconstruindo o conhecimento. Estudos Feministas 2008; 16(1): 229-245.

30. Villela W, Monteiro S. Gênero e Saúde. Programa Saúde da Família em questão. Rio de Janeiro: ABRASCO; Brasília: UNFPA; 2005.

31. Mendes-Gonçalves RB. Tecnologia e Organização das Práticas de Saúde: características tecnológicas do processo de trabalho na rede estadual de Centros de Saúde de São Paulo. Rio de Janeiro: Abrasco; São Paulo: Hucitec; 1994.

32. Nunes ED. Tendências e Perspectivas das pesquisas em Ciências Sociais em Saúde na América Latina: uma visão geral. In: Nunes ED, organizador. As Ciências Sociais em Saúde na América Latina. Tendências e Perspectivas. Brasília: OPAS; 1985. p. 31-79.

33. Ayres JRCM. Sobre o risco. Para compreender a Epide miologia. São Paulo: Hucitec; 1995.

34. Schraiber LB, M ota A, N ovaes HM D. Tecnologias em Saúde. In: Escola Politécnica de Saúde Joaquim Venâncio, organizadora. Dicionário da educação profissional em saúde. Rio de Janeiro: Fiocruz; 2006. p. 248257.

Artigo apresentado em 19/11/2008

Aprovado em 11/02/09

Versão final apresentada em 03/04/09 